\title{
How to reach the gold standard in prophylaxis: Guided Biofilm Therapy
}

Lately, more and more dental equipment companies have created associations to educate their users so as to increase the visibility of their products.

Thus, EMS - Electro Medical Systems S.A., a Swiss company, in an attempt to disseminate the unique Guided Biofilm Therapy (GBT) prophylaxis concept based on the scientific studies of Per Axelsson and Jan Lindhe1-3 from the Göteborg University, Sweden founded the Swiss Dental Academy. It provides practitioners with training courses for them to adopt a clinical protocol for the guided biofilm treatment and best patient care practices. Since its creation in 2005, it has trained over 35,000 practitioners from over 25 countries around the world. I have also been the recipient of such a guided biofilm management course.

During the IDS 2017, out of a multitude of dental prophylaxis devices, I noticed the the Ultra-Compact Prophylaxis Station+ at the EMS stand. The device is based on the Airflow ${ }^{\circledR}$ Prophylaxis Master developed by the EMS Research Center following over 100,000 hours of technical and clinical testing in collaboration with top dental professionals around the world. The device was designed to meet the highest standards of performance, safety and comfort, being built to meet the 3 basic treatments of the Guided Biofilm Therapy (GBT):

1. Removing supragingival biofilms, stains and young calculus from natural teeth, restorations and implants. It is performed in a single cleaning and polishing procedure with the Airflow Handpiece made of medical-grade resin bodies and new generation thermo-disinfectable materials;

2. Removing subgingival biofilms from periodontal and peri-implant pockets from 4 to $9 \mathrm{~mm}$. It is carried out with the Perioflow ${ }^{\circledR}$ Handpiece and Plus powder which ensures effective elimination of the biofilm, sustained reduction in bacteria, prevention of tooth loss or loss of implants;

3. Removing the supra and subgingival residual calculus. It is done with the ergonomic Piezon ${ }^{\circledR}$ Led instrument based on the revolutionary No-Pain technology, ideal for conservative treatments and minimally invasive therapies. The instrument has an optimal diameter with a narrow tip for better visibility and accessibility, alongside a 5,0000 Kelvin built-in lamp that provides natural light. All the unique EMS Piezon tips are made of surgical stainless steel.

In addition to the qualities of Airflow ${ }^{\circledR}$ Prophylaxis Master, the Ultra-Compact Prophylaxis Station+ has the following advantages:

- Pressurization Tower

Automatic pressurization system pressurizing and depressurizing within seconds with a $360^{\circ}$ integrated magnetic connection.

- Interactive Touch Panel

Simple and ergonomic touch panel comes with a 10 level responsive interface that regulates and manually adjusts temperature and volume control feature with operating sound notifications and maintenance reminder.

- New Cord

Durable and more efficient, the new EMS cord has a 'plug-and-play' system that is easily detachable and simple to service.

- Foot-Pedal Wireless

Wireless stainless steel foot-pedal with boost mode and $360^{\circ}$ power activation access.

- External Filters

Transparent air \& water filters allowing for an easy check at a glance.

- Purge System

Completely integrated Airflow ${ }^{\circledR}$ and Piezon ${ }^{\circledR}$ waterline purge system cleans fluid lines in under a minute.

- New No Pain Technology

Dynamic response feature automatically regulating the output power according to the required force to remove calculus.

- Seamless Design

Easy to clean and maintain. All cables are stored in the station to eliminate trip hazards.

- Ultra-compact

Efficient space management.

- Independent Bottled Water Supply

No need for an external water connection.

- Easy to Move and Store

$360^{\circ}$ movement.

- Extra Storage Space

For additional powder bottles.

The Ultra-Compact Prophylaxis Station+ is an effective alternative to reach the gold standard in prophylaxis: Guided Biofilm Therapy (GBT).

Florin - Eugen Constantinescu DMD, PhD Student Editorial Director, Product News

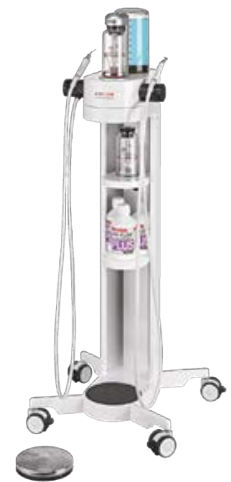

The Ultra-Compact Prophylaxis Station+ (EMS - Electro Medical Systems S.A., CH-1260 Nyon, Switzerland) https://www.ems-dental.com/en/accessories/airflow-station-plus

\section{References}

1. Axelsson $P$, Nyström $B$, Lindhe J. The long-term effect of a plaque control program on tooth mortality, caries and periodontal disease in adults. Results after 30 years of maintenance. J Clin Periodontol. 2004;31(9):749-757. doi: 10.1111/j.1600-051X.2004.00563.x

2. 2. Paulander J Wennström JL, Axelsson $P$, Lindhe J. Some risk factors for periodontal bone loss in 50-year-old individuals. A 10-year cohort study. J Clin Periodontol. 2004;31(7):489-496. doi: 10.1111/j.1600051X.2004.00514 x

3. 3. Ramberg P, Axelsson P, Lindhe J. Plaque formation at healthy and inflamed gingival sites in young individuals. $J$ Clin Periodontol. 1995;22(1):85-88.

DOI: 10.25241/stomaeduj.2017.4(4).prodnews.1 